\title{
Particulate matter delivers nutrients and heavy metals to the Colorado Front Range, USA
}

\author{
Ruth C. Heindel ${ }^{1}$, ANNie L. Putman ${ }^{2}$, Sheila F. \\ MURPHY $^{3}$, DEBORAH A. REPERT ${ }^{3}$, EVE-LYN S. \\ HINCKLEY ${ }^{4}$ \\ ${ }^{1}$ Environmental Studies Program, Kenyon College, Gambier, \\ OH, 43022, heindel1@kenyon.edu \\ ${ }^{2}$ U.S. Geological Survey, Utah Water Science Center, West \\ Valley City, UT, 84119 \\ ${ }^{3}$ U.S. Geological Survey, Water Mission Area, Boulder, CO, \\ 80303,sfmurphy@usgs.gov and darepert@usgs.gov \\ ${ }^{4}$ Institute of Arctic and Alpine Research, University of \\ Colorado Boulder, Boulder, CO 80303, \\ eve.hinckley@colorado.edu
}

Particulate matter (PM) in atmospheric deposition can be a significant source of nutrients and pollutants to arid and semi-arid ecosystems. Previous studies have established the importance of PM deposition for Rocky Mountain ecosystems, but have not yet constrained the spatial and temporal variability in PM fluxes. We present PM composition and back-trajectory modelling results from two years of bulk (wet plus dry) deposition sampling across an elevation gradient in the Colorado Front Range. To partition elemental fluxes between liquid and PM fractions, we filtered samples and analysed the fractions separately. We found that PM was enriched in $\mathrm{P}, \mathrm{S}, \mathrm{Cu}, \mathrm{Zn}, \mathrm{Pb}, \mathrm{Li}, \mathrm{Mo}$, and $\mathrm{Cd}$ relative to the composition of the upper continental crust; enrichment factors for these elements ranged from 1.3 to 50 . For the nutrients $\mathrm{K}, \mathrm{Mg}$, and $\mathrm{P}, \mathrm{PM}$ accounted for more than half of the total bulk depositional fluxes. Seasonal and elevational differences in the composition of PM corresponded to different back-trajectory footprints, suggesting greater contributions from urban and agricultural sources in spring and summer compared to fall and winter. Our results highlight the potential for urban and agriculturally sourced PM to deliver limiting nutrients and metals to adjacent ecosystems, including sensitive wilderness areas and water supplies. 